\title{
FcyRIII engagement provides activating signals to NKT cells in antibody-induced joint inflammation
}

\author{
Hye Young Kim,, ${ }^{1,2}$ Sanghee Kim, ${ }^{3}$ and Doo Hyun Chung1,2 \\ 1Department of Pathology and 2Laboratory of Immune Regulation, Graduate Program of Immunology, Seoul National University College of Medicine, \\ Seoul, Republic of Korea. ${ }^{3}$ Natural Products Research Institute, College of Pharmacy, Seoul National University, Seoul, Republic of Korea.
}

\begin{abstract}
NKT cells promote antibody-induced arthritis, but the mechanism by which NKT cells are activated in this model remains unclear. It has been proposed that $\mathrm{Fc} \gamma$ receptor $(\mathrm{Fc} \gamma \mathrm{R})$ contributes to NKT cell activation in antibody-induced arthritis. To address this issue, we explored the functions of Fc $\gamma$ R on NKT cells in antibody-induced arthritis. RT-PCR and flow cytometric analysis demonstrated that NKT cells constitutively express surface Fc $\gamma$ RIII but not Fc $\gamma$ RI, -II, or -IV. Fc $\gamma$ RIII engagement by aggregated IgG on NKT cells enhanced CD25 and CD69 expression, whereas $F c \gamma R^{-/-}$mouse NKT cells did not enhance activation. Fc $\gamma$ RIII engagement on NKT cells enhanced the production of IL-4, IL-10, IL-13, and IFN- $\gamma$, whereas Fc $\gamma R$ deficient NKT cells did not alter the production of these cytokines after aggregated IgG treatment. However, $F c \gamma R$-deficient NKT cells were functionally intact in terms of TCR-induced activation. Moreover, adoptive transfer of $F c \gamma R$-deficient NKT cells could not restore inflammation or TGF- $\beta$ production in the joint tissues of $C D 1 d^{-/-}$mice, whereas adoptive transfer of wild-type NKT cells induced arthritis and reduced TGF- $\beta$ production in joint tissues. We conclude that Fc $\gamma$ RIII engagement by IgG in joint tissues provides activating signals to NKT cells in antibody-induced arthritis.
\end{abstract}

\section{Introduction}

NKT cells express intermediate levels of a semi-invariant

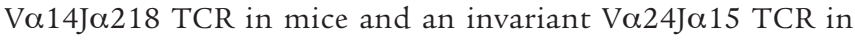
humans (1), which recognizes glycolipid antigens presented by CD1d molecules (2). The $\alpha$-galactosyl ceramide ( $\alpha$-GalCer) binds to CD1d and these complexes are recognized by the TCR of NKT cells (3). Upon activation, NKT cells rapidly produce large amounts of IL-4 and IFN- $\gamma$ (4), which play critical roles in the regulation of immune responses by NKT cells (5). In animal models, NKT cells have been reported to affect the development and progression of diabetes mellitus (6), experimental autoimmune encephalitis (7), rheumatoid arthritis (8), pulmonary fibrosis (9), and lupus (10).

NKT cells play an indispensable role in the induction of antibody-induced joint inflammation by suppressing TGF- $\beta 1$ production in joint tissues, which in turn is dependent on IL-4 and IFN- $\gamma$ secreted by NKT cells (8). In addition, $\alpha$-GalCer slightly enhanced arthritis in C57BL/6 (B6) mice of the KRN TCR transgenic mice of C57BL/6 (B6) background $\times$ NOD mice $(\mathrm{K} / \mathrm{BxN}$; see Methods) serum transfer mouse model, which suggested that TCR engagement on NKT cells may contribute to NKT cell activation in this model. Therefore, we speculated that cellular glycolipids provided by apoptotic cells during the development of arthritis are presented to TCR on NKT cells by CD1d-expressing cells in vivo and thus activate NKT cells to secrete IL- 4 and IFN- $\gamma$. This speculation is supported by several reports that demonstrate that CD1d molecules are able to present cellular glycolipid to activate NKT cells (11). However, it is unclear whether TCR engagement

Nonstandard abbreviations used: B6, C57BL/6; DN, double-negative; FC $\gamma$ R, Fcy receptor; $\alpha$-GalCer, $\alpha$-galactosyl ceramide; iNKT, invariant NKT; K/BxN, KRN TCR transgenic, B6 $\times$ NOD background; MNC, mononuclear cell.

Conflict of interest: The authors have declared that no conflict of interest exists. Citation for this article: J. Clin. Invest. 116:2484-2492 (2006). doi:10.1172/JCI27219. on NKT cells provides the critical activating signals to NKT cells in the $\mathrm{K} / \mathrm{BxN}$ serum transfer model. Alternatively, it is feasible that $\mathrm{Fc} \gamma$ receptor $(\mathrm{Fc} \gamma \mathrm{R})$ engagement provides potent activating signals to NKT cells independently of simultaneous TCR stimulation in vivo. Moreover, $\mathrm{FC}_{\mathrm{C} R I I I^{-/-}}$mice show a slowly progressing arthritis, which suggests that Fc $\gamma$ RIII is responsible for the development of antibody-induced arthritis $(12,13)$. Unlike conventional $\mathrm{T}$ cells, NKT cells are characterized by the expression of Fc $\gamma$ RIII, a potent activating receptor on NK cells that contains an immunoreceptor tyrosine-based activation motif (ITAM) in its cytoplasmic domain $(14,15)$. Thus, we hypothesized that IgGs deposited against antigens in joint tissues are recognized by NKT cells through FcyR independently of TCR signals and that the signals generated by Fc $\gamma$ R activate NKT cells to produce cytokines and contribute to joint inflammation. To address this hypothesis, we investigated whether Fc $\gamma$ R on NKT cells contribute to NKT cell activation in a $\mathrm{K} / \mathrm{BxN}$ serum transfer model.

Here we show that Fc $\gamma$ RIII engagement on NKT cells enhances CD25 and CD69 expression and cytokine production in vitro. Moreover, the adoptive transfer of $F c \gamma R$-deficient NKT cells does not restore joint inflammation of $C D 1 d^{-/}$mice, whereas wild-type NKT cells induce arthritis in the antibody-induced joint inflammation model. Taken together, these findings indicate that FcyRIII engagement by IgG in joint tissues provides activating signals to NKT cells in antibody-induced arthritis.

\section{Results}

NKT cells constitutively express surface Fc $\gamma$ RIII. To investigate the functional roles of $\mathrm{Fc} \gamma \mathrm{R}$ in NKT cell activation in the K/BxN serum transfer model, we explored in detail the expression pattern of Fc $\gamma$ R on sorted hepatic NKT cells from B6 mice containing all subpopulations of NKT cells. These hepatic NKT and NK cells expressed $F c \gamma R I I I$ mRNA but not $F c \gamma R I$, -II, or - IV mRNA (Figure 1A) 
A

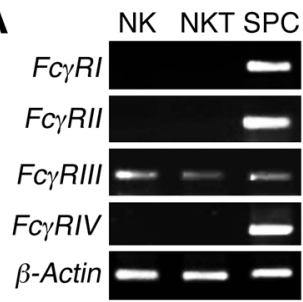

B
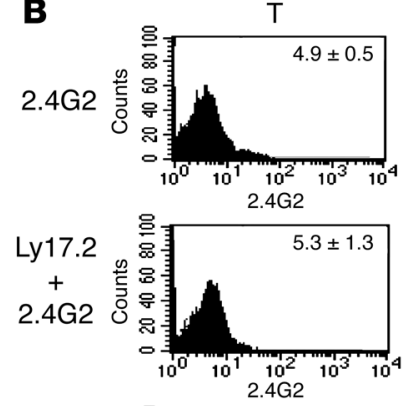

Ly17.2

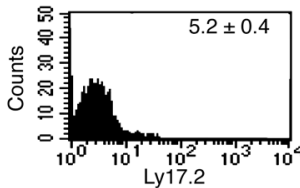

C

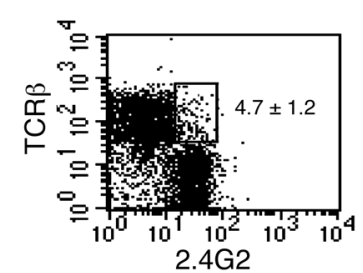

D
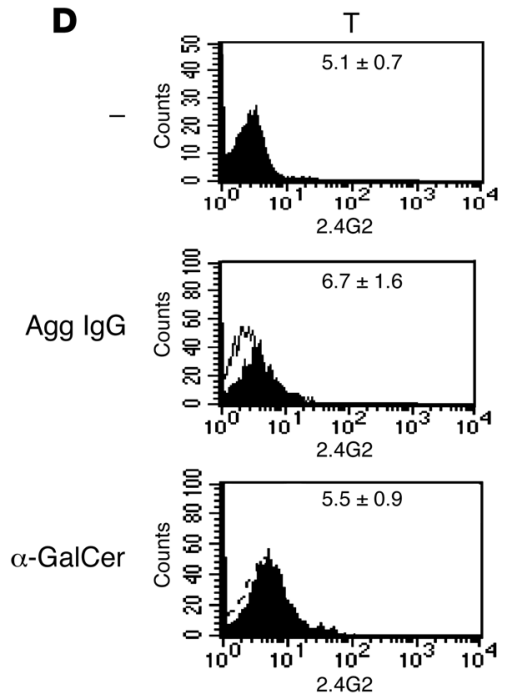
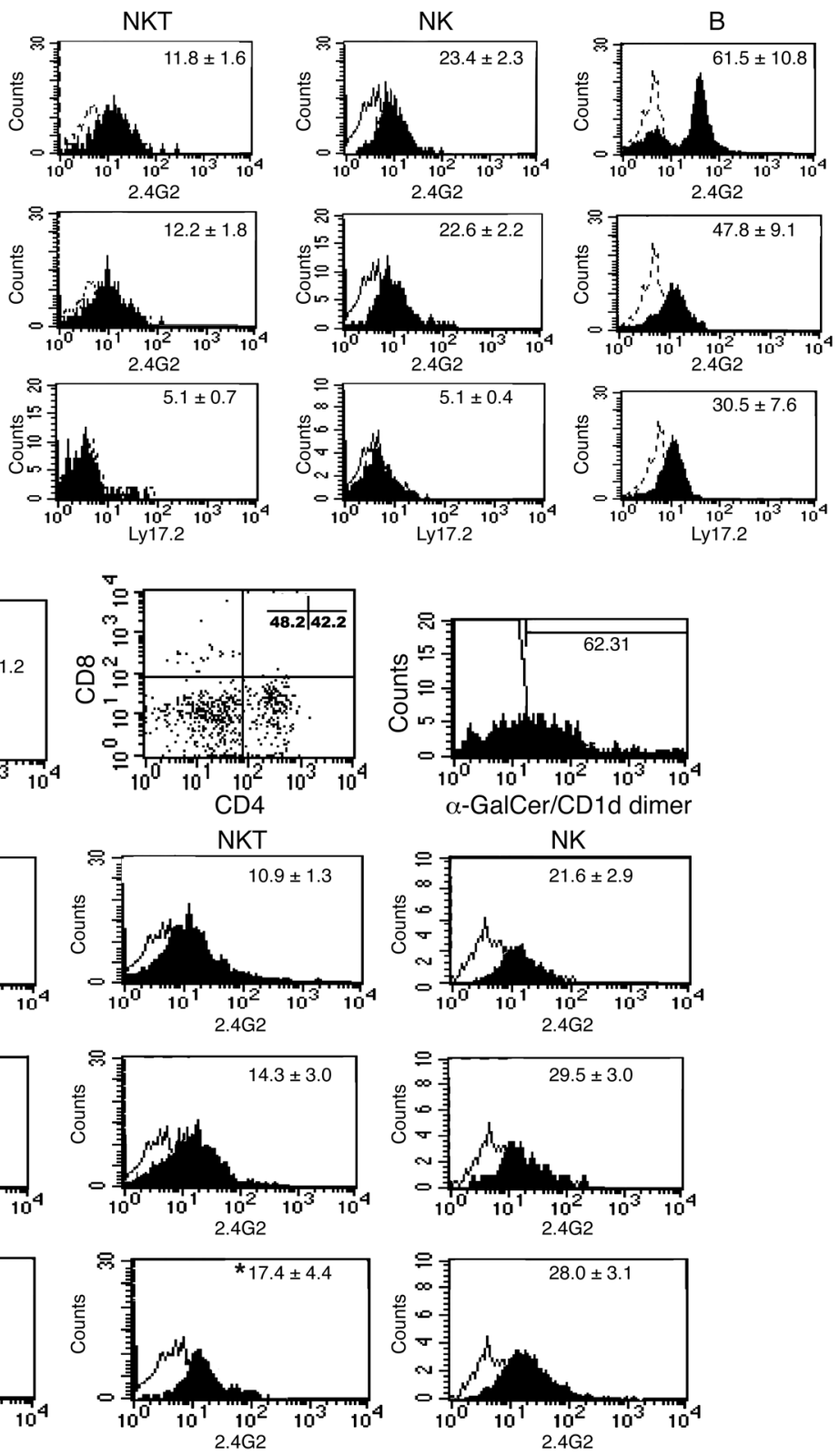

Figure 1

NKT cells constitutively express surface FcyRIII. (A) F $\gamma \gamma R I$, -II, -III, and -IV expression on sorted NK1.1+TCR $\beta+$ NKT cells, NK1.1+TCR $\beta$ - NK cells, and splenocytes (SPC) freshly isolated from B6 mice was analyzed by RT-PCR. (B) FcyRll and FcyRIII expression was analyzed on gated NKT cells, NK cells, NK1.1-TCR $\beta^{+}$T cells, and B220+ B cells using 2.4G2 or Ly17.2 mAb. Cells were also preincubated with Ly17.2 mAb and stained with 2.4G2. As a negative control, cells were stained with isotype-matched IgG for 2.4G2 or Ly17.2 mAbs (open histogram). Numbers indicate mean fluorescence intensity (MFI) $\pm \mathrm{SD}$. (C) The expression of CD4/CD8 or Va14+TCR was analyzed on gated TCR $\beta^{+} 2.4 \mathrm{G} 2^{+}$liver MNCs using anti-CD4 and CD8 mAb or $\alpha$-GalCer/CD1d dimer. Numbers indicate percent of cells \pm SD. (D) Liver MNCs were freshly isolated from B6 mice and cultured with $\alpha$-GalCer $(220 \mathrm{ng} / \mathrm{ml})$ or aggregated IgG (Agg lgG; $10 \mu \mathrm{g} / \mathrm{ml})$ for 24 hours. FcyRIII expression was analyzed on gated NKT, $\mathrm{NK}$, and T cells. Open histograms represent negative controls, which were stained with anti-NK1.1 and -TCR $\beta$ mAbs and isotype-matched IgG for 2.4G2. Numbers indicate MFI \pm SD. Results are representative of 3 independent experiments. ${ }^{*} P<0.05$.

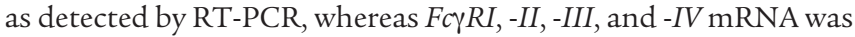
detected in splenocytes. FcyRIII surface expression was confirmed on hepatic NKT and NK cells by flow cytometric analysis using 2.4G2 (Figure 1B), a mAb that specifically reacts with FcyRII and -III (16). To confirm the specific expression of Fc $\gamma$ RIII on NKT cells, liver mononuclear cells (MNCs) were preincubated using a Ly17.2 mAb that specifically binds FcrRII molecules and stained using 2.4G2. The fluorescence intensities of 2.4G2 on NK and NKT cells were not reduced by preincubation with Ly17.2 mAb, whereas those on B cells were attenuated (Figure 1B). Moreover, the expression of Fc $\gamma$ RII molecules was not found on $\mathrm{T}, \mathrm{NK}$, or NKT cells, whereas B cells expressed FcyRII on the cell surface. These findings indicate that hepatic NK and NKT cells express

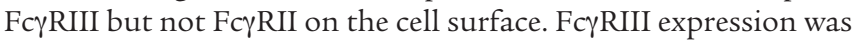


A
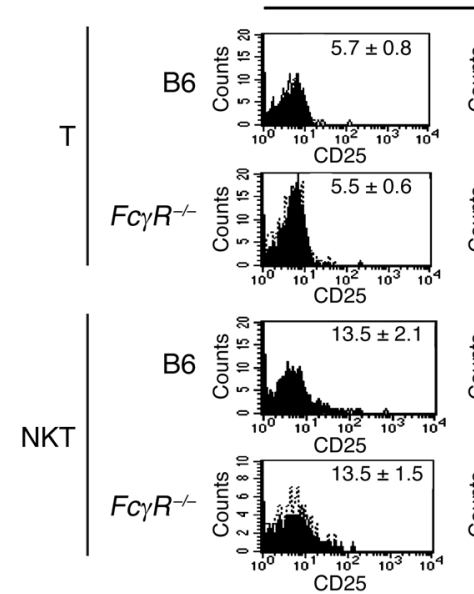

B6
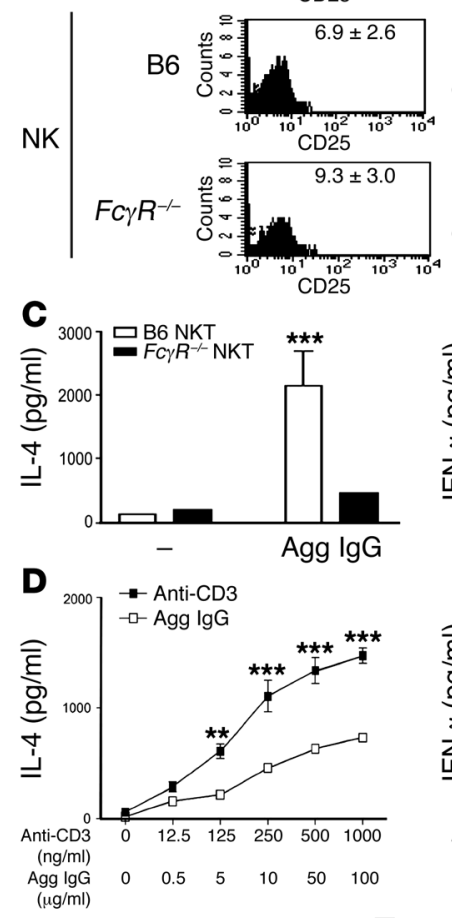
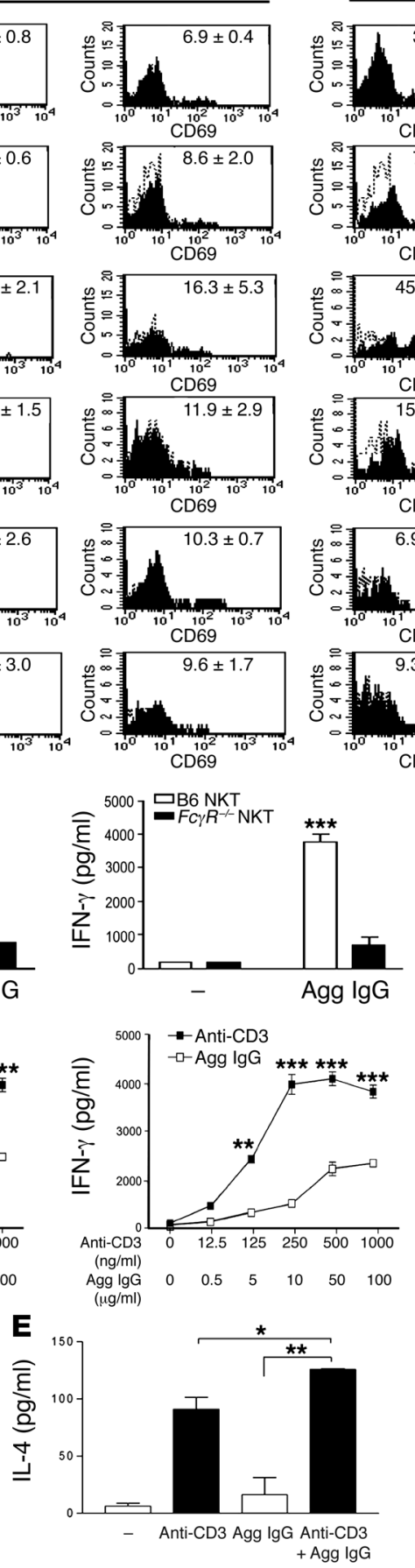

Agg $\lg G$
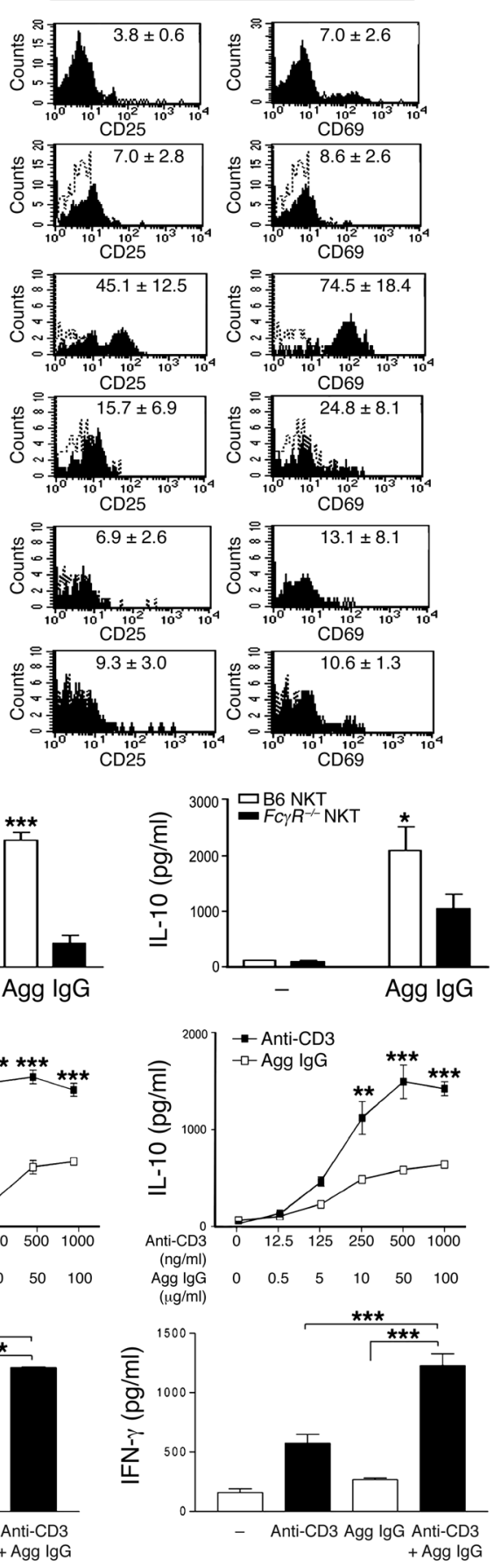

B
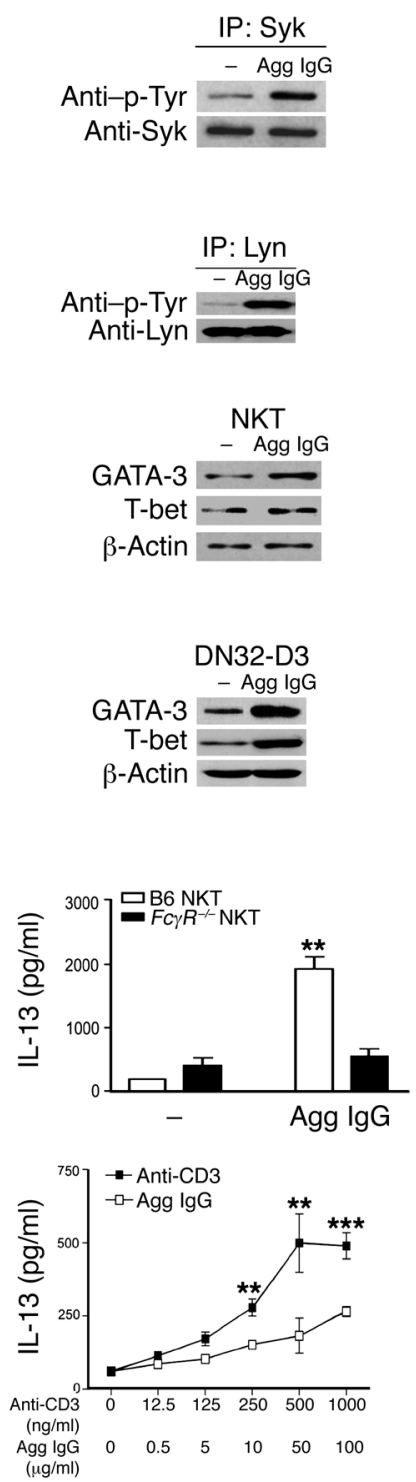

$($ (ug/ml)

Figure 2

FcyRIII engagement activates NKT cells. (A) Liver MNCs from B6 or $F c \gamma R^{-/-}$mice were cultured with or without (-) aggregated lgG (10 $\left.\mu \mathrm{g} / \mathrm{ml}\right)$, and CD25 and CD69 expression was analyzed 24 hours after stimulation. Open histograms represent negative controls, in which cells were stained with anti-NK1.1 and -TCR $\beta$ mAbs and isotype-matched IgG for anti-CD25 or -CD69 mAb. Numbers indicate MFI \pm SD, from 3 independent experiments. (B) DN32-D3 cells were stimulated with or without aggregated IgG for 2 hours, lysed, and immunoprecipitated with anti-Syk or -Lyn mAb followed by anti-phosphotyrosine (anti-p-Tyr). The same cell lysates were directly blotted using anti-Syk or -Lyn mAb. Sorted NKT and DN32-D3 cells were stimulated with and without aggregated IgG for 24 hours, and the total proteins were separated by SDS-PAGE and immunoblotted using anti-T-bet or-GATA-3 mAbs. (C) Sorted NKT cells from B6 or $F c \gamma R^{-1-}$ mice $\left(1 \times 10^{5}\right.$ cells/well) were stimulated with aggregated IgG for 48 hours. The amounts of IL-4, IFN- $\gamma$, IL-10, and IL-13 in the culture supernatant were measured using ELISA. (D) Sorted NKT cells from B6 mice $\left(1 \times 10^{5}\right.$ cells/well) were cultured with aggregated IgG or anti-CD3 mAb at the indicated concentrations, and the amounts of IL-4, IFN- $\gamma$, IL-10, and IL-13 measured using ELISA. (E) The same cells as in D were cultured with aggregated lgG $(10 \mu \mathrm{g} / \mathrm{ml})$, anti-CD3 $\mathrm{mAb}(100 \mathrm{ng} / \mathrm{ml})$, or both for 48 hours. The amounts of IL-4 and IFN- $\gamma$ were measured using ELISA. Results are representative of 3 independent experiments. ${ }^{*} P<0.05 ;{ }^{* \star} P<0.01 ;{ }^{* * \star} P<0.001$. 
lower on hepatic NKT cells than on NK cells. In addition, the expression pattern of Fc $\gamma$ R on NKT cells derived from the thymus and spleen was similar to that on NKT cells from the liver as determined by flow cytometric analysis (data not shown). The NKT hybridoma double-negative 32-D3 (DN32-D3) cells expressed $F c \gamma R I I$ and -III mRNA but not $F c \gamma R I$ mRNA, as confirmed by flow cytometric analysis (data not shown). The FcyRIII ${ }^{+}$NKT cells were either $\mathrm{CD}^{+}{ }^{+} \mathrm{CD}^{-}$(42.2\%) or $\mathrm{CD}^{-}{ }^{-} \mathrm{CD}^{-}{ }^{-}$(48.2\%), whereas CD4-CD8 ${ }^{+}$Fc $\gamma \mathrm{RIII}^{+} \mathrm{NKT}$ cells were barely found in the liver. It has been reported that $\mathrm{CD}^{-}{ }^{-} \mathrm{CD} 8^{-} \mathrm{DN} N \mathrm{NK} 1.1^{+} \mathrm{T}$ cells express Fc $\gamma \mathrm{RIII}$ but not Fc $\gamma$ RII, which is consistent with the FcyR expression pattern on hepatic NKT cells (15). In addition, $62.3 \%$ of Fc $\gamma \mathrm{RIII}^{+} \mathrm{NKT}$ cells were reactive for $\alpha$-GalCer/CD1d dimer (Figure 1C). These findings indicate that $\mathrm{F} c \gamma \mathrm{RIII}^{+} \mathrm{NKT}$ cells are a mixed population of cells that consist of invariant NKT (iNKT) and non-iNKT cells. Taken together, these findings show that NKT cells constitutively express Fc $\gamma$ RIII, but not FcyRI, -II, or -IV, on the cell surface in amounts lower than those on NK cells.

Next, to determine whether activating signals through TCR or Fc $\gamma$ RIII on NKT cells upregulate Fc $\gamma$ RIII expression, liver MNCs isolated from $\mathrm{B} 6$ mice were treated with $\alpha$-GalCer or aggregated IgG in vitro. FcyRIII surface expression on NKT cells was significantly upregulated upon TCR engagement by $\alpha$-GalCer/CD1d $(P<0.05)$, whereas Fc $\gamma$ RIII surface expression on NK cells or conventional T cells was not enhanced after $\alpha$-GalCer treatment $(P>0.05$; Figure 1D). In addition, aggregated IgG did not upregulate the expression level of FcyRIII (Figure 1D) and TCR (data not shown) on NKT cells. These findings indicate that the constitutive expression of Fc $\gamma$ RIII on NKT cell surfaces is upregulated by TCR stimulation.

Fc $\gamma R I I I$ engagement induces NKT cell activation independently of TCR stimulation. To examine whether Fc $\gamma$ RIII engagement activates NKT cells, the expression levels of activating markers such as CD25 and CD69 on NKT, T, and NK cells from B6 and $F c \gamma R^{-/-}$mice were measured after Fc $\gamma$ RIII engagement by aggregated IgG. $F c \gamma R^{-/-}$mice are deficient in Fc $\gamma$ RI, Fc $\gamma$ RIII, Fc $\gamma$ RIV, and FceRI expression because the deleted $\gamma$ chain subunit is essential for the cell surface expression of these molecules $(17,18)$. Therefore, NKT cells from $F c \gamma R^{-1-}$ mice lack Fc $\gamma$ RIII expression on the cell surface. Fc $\gamma$ RIII engagement enhanced CD69 and CD25 expression on B6 mouse NKT cells, whereas $F c \gamma R^{-/-}$mouse NKT cells showed no CD69 or CD25 upregulation (Figure 2A). However, noncomplexed IgG did not alter cytokine production or activation marker expression of NKT cells, suggesting that crosslinking of Fc $\gamma$ RIII engagement is critical to activate NKT cells through Fc $\gamma$ RIII (data not shown). Moreover, aggregated IgG did not upregulate CD69 and CD25 expression on $\mathrm{T}$ and NK cells from $\mathrm{B} 6$ and $F c \gamma R^{-/-}$mice (Figure $2 \mathrm{~A}$ ).

To investigate whether Fc $\gamma$ RIII engagement induces signal transduction enhancement in NKT cells, we measured the phosphorylation status of Syk and Lyn kinases, which are components of the signal transduction through Fc $\gamma$ RIII, in DN32-D3 cells after aggregated IgG treatment. FcyRIII engagement results in the tyrosine phosphorylation of ITAM by members of the SRC kinase family, which subsequently recruits cytosolic protein kinases containing the SH2 domain, most notably Syk and Lyn $(19,20)$. We found that Fc $\gamma$ RIII engagement on DN32-D3 cells increased the phosphorylation of Syk and Lyn in total cell lysates (Figure 2B). These findings suggest that Fc $\gamma$ RIII engagement provides activating signals to NKT cells through Syk and Lyn phosphorylation.
To functionally evaluate the effects of NKT cells activated through FcyRIII, we measured the amounts of the cytokines produced by NKT cells stimulated with aggregated IgG. Fc $\gamma$ RIII engagement significantly enhanced the production of IL-4, IFN- $\gamma$, IL-10, and IL-13 by NKT cells from B6 mice, whereas NKT cells from $F c^{-1-}$ mice showed less production of these cytokines after aggregated IgG treatment (Figure 2C). These findings indicate that production of all cytokines in response to aggregated IgG by B6 NKT cells is significantly greater than that of $F c \gamma R^{-/-}$NKT cells. Consistent with these findings, Fc $\gamma$ RIII engagement increased the expression of the transcription factors T-bet and GATA-3 in the sorted NKT cells and DN32-D3 cells (Figure 2B), factors critical for the production of Th1/ Th2 cytokines in immune cells $(21,22)$. Taken together, these findings demonstrate for the first time to our knowledge that FcrRIII engagement provides potent activating signals to NKT cells independently of simultaneous TCR stimulation and that this engagement results in enhanced cytokine production.

To investigate in more detail the effects of TCR and FcrRIII stimulation on NKT cells, we compared the relative strengths of the activating signals from TCR and FC $\gamma$ RIII on NKT cells by measuring cytokine production after stimulating liver MNCs of B6 mice with anti-CD3 mAb or aggregated IgG. Maximal production of IL-4, IFN- $\gamma$, IL-10, and IL-13 in NKT cells stimulated with anti-CD3 $\mathrm{mAb}$ were higher than those in NKT cells stimulated with aggregated IgG (Figure 2D). These findings suggest that the relative strengths of activating signals in NKT cells through TCR engagement appeared stronger than those through Fc $\gamma$ RIII engagement in terms of cytokine production. Alternatively, the difference in surface receptor expression of TCR and Fc $\gamma$ RIII on NKT cells is also possible to explain the weaker cytokine response following Fc $\gamma$ RIII ligation. Nevertheless, Fc $\gamma$ RIII engagement provided signaling sufficient to activate NKT cells without the involvement of TCR signals and thus may contribute to the modulation of immune responses in vivo. Next, to explore whether the simultaneous engagement of TCR and Fc $\gamma$ RIII exerts effects on NKT cell activation, sorted NKT cells were cultured with suboptimal concentrations of anti-CD3 $\mathrm{mAb}$ and/or aggregated IgG, and cytokine production was measured in culture supernatant. When cultured alone, both TCR and Fc $\gamma$ RIII engagement activated NKT cells to produce IL-4 and IFN- $\gamma$. The activation signals through both TCR and FcyRIII on NKT cells enhance cytokine output significantly compared with activation signals through TCR or Fc $\gamma$ RIII alone on NKT cells. However, the amount of these cytokines produced by NKT cells activated by simultaneous engagement of TCR and FcyRIII was similar to the total amounts of cytokines produced by NKT cells activated using anti-CD3 $\mathrm{mAb}$ or aggregated IgG alone (Figure $2 \mathrm{E}$ ).

The engagement of Fc $\gamma$ RIII on NKT cells promotes antibody-induced arthritis. To determine whether the effects of FcyRIII engagement on NKT cells play a critical role in antibody-induced arthritis, we examined joint inflammation in $C D 1 d^{-/-}$mice administered NKT cells from $\mathrm{B} 6$ or $\mathrm{Fc} \gamma \mathrm{R}^{-/-}$mice after $\mathrm{K} / \mathrm{BxN}$ serum transfer. As previously reported, B6 mice showed measurable joint swelling at 4-5 days and maximal swelling at 8-9 days after serum transfer, whereas $C D 1 d^{-/-}$mice were resistant to the development of arthritis (8). However, $C D 1 d^{-/-}$mice administered NKT cells from B6 mice showed measurable swelling, like that of B6 mice, and CD1 ${ }^{-/-}$ mice administered NKT cells from $F_{c \gamma} R^{-/-}$mice showed minimal joint swelling, like that of $C D 1 d^{-/-}$mice (Figure 3, A and B). 


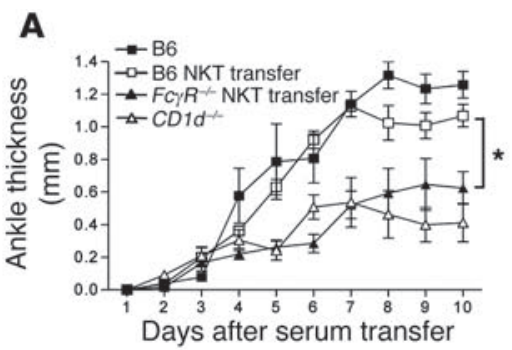

B $\quad$ B6

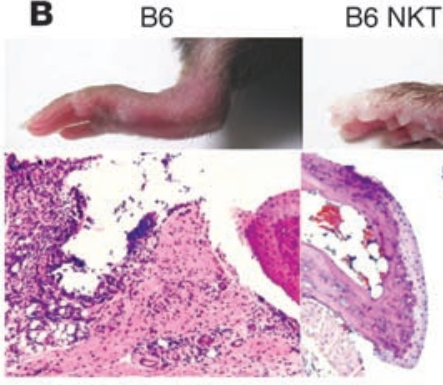

B6

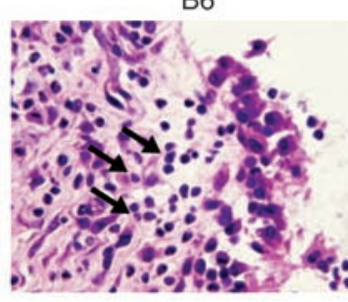

D
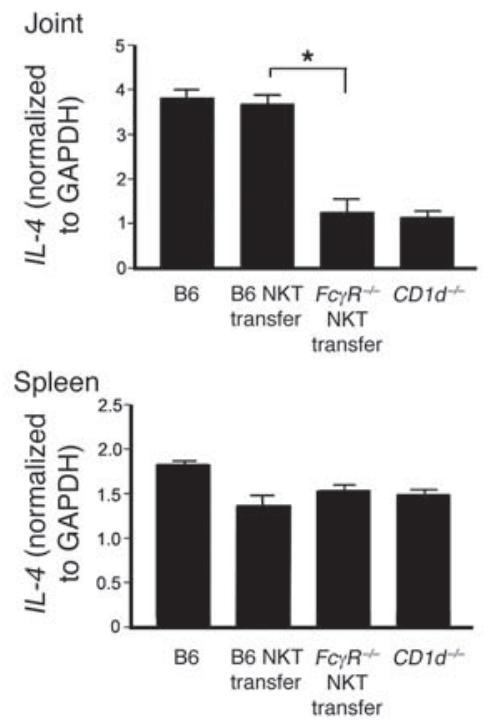

ransfer

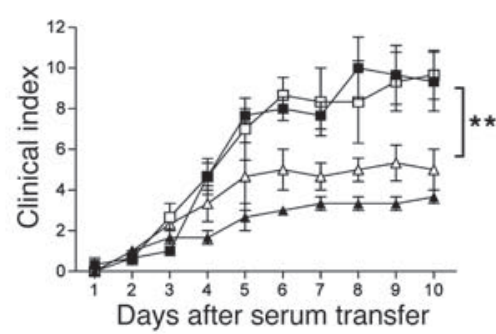

F c $R^{-1-N K T ~ t r a n s f e r ~}$

$C D 1 d^{-1}$
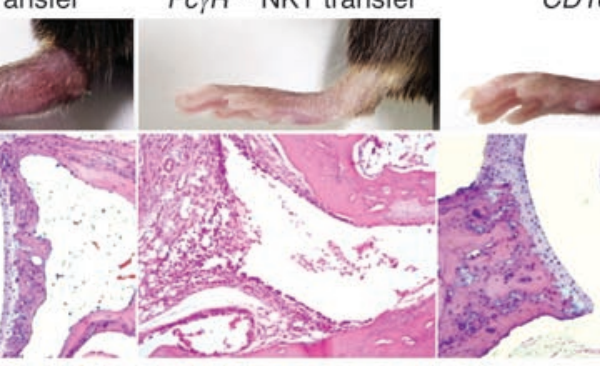

B6 NKT transfer
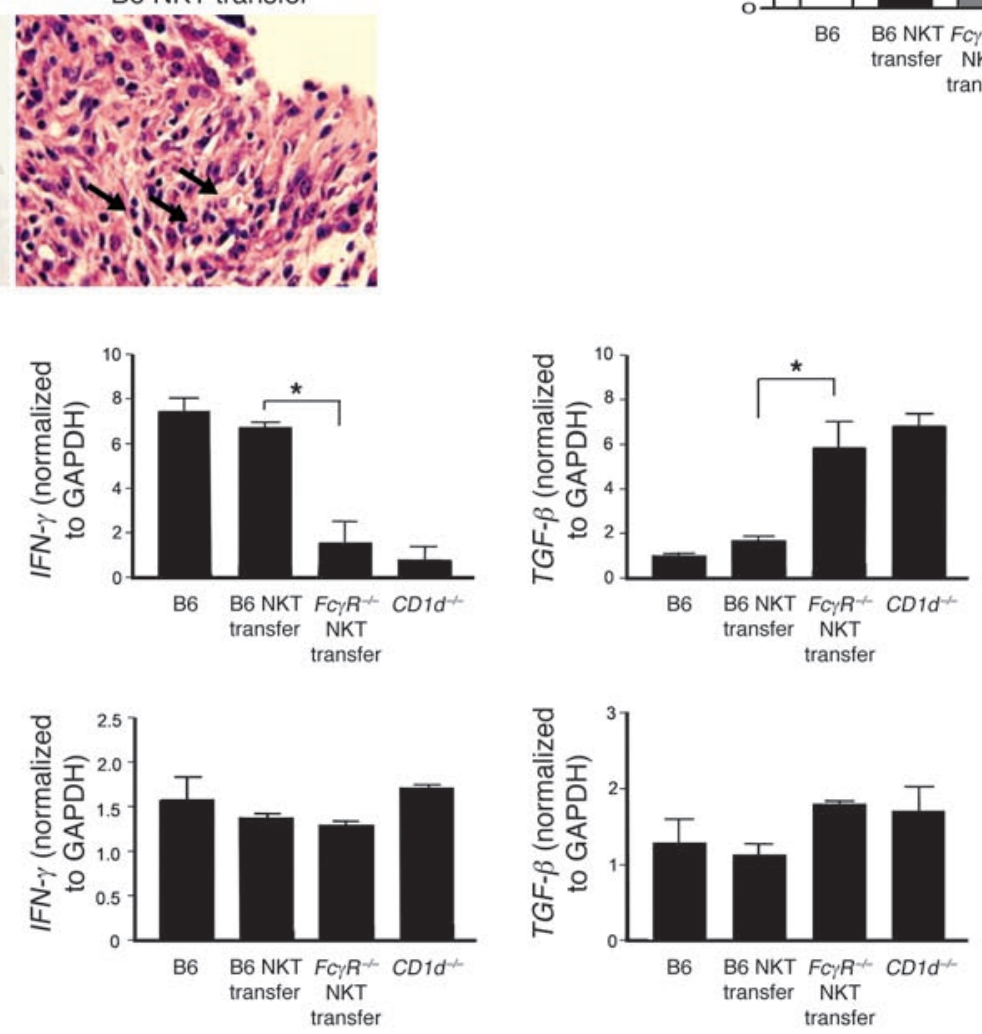

C

B6 NKT NKT

B6 transfer transfer $\mathrm{CD}_{1 d^{-}}$

V 14 TCR $\longrightarrow$

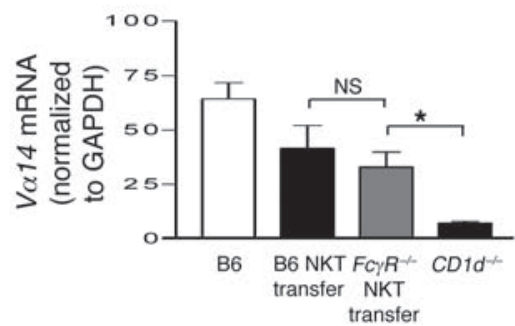

Figure 3

Adoptive transfer of $F C \gamma R^{-/-}$mouse NKT cells into $C D 1 d^{-1-}$ mice does not restore joint inflammation in a $\mathrm{K} / \mathrm{BxN}$ serum transfer model. (A) Sorted NKT cells $\left(3 \times 10^{5}\right.$ cells/mouse) from B6 or $F c \gamma R^{-/-}$mice were adoptively transferred into $C D 1 d^{-/-}$mice (B6 NKT transfer or $F c \gamma R^{-/-}$NKT transfer, respectively) 1 day before the $\mathrm{K} / \mathrm{BxN}$ serum transfer ( $n=5$ per group). Clinical scores and ankle thickness were monitored in B6 and $C D 1 d^{-/-}$mice as well as in $C D 1 d^{-/-}$mice administered NKT cells of $\mathrm{B} 6$ or $F \mathrm{c} \gamma \mathrm{R}^{---}$mice after injecting $\mathrm{K} / \mathrm{BxN}$ serum. (B) Histological and gross examination of the ankle joints of $B 6$ and $C D 1 d^{-/-}$mice as well as $C D 1 d^{-/-}$mice administered $B 6$ or $F C \gamma R^{-/-}$mouse NKT cells 5 days after serum transfer. Original magnification, $\times 200$ (middle panels); $\times 1,000$ (bottom panels). Arrows in bottom panels indicate neutrophils in the joint tissues.

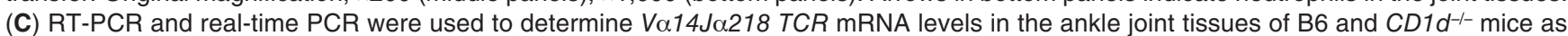
well as $C D 1 d^{-/-}$mice administered $\mathrm{B} 6$ or $F C \gamma R^{-/-}$mouse NKT cells. RT-PCR and real-time PCR were performed 10 days after $\mathrm{K} / \mathrm{B} \times \mathrm{N}$ serum transfer. (D) TGF- 1 1, IL-4, and IFN- $\gamma$ mRNA levels were measured by real-time PCR in the joint tissues and spleens of B6 mice, $C D 1 d^{-/-}$mice, and $C D 1 d^{-1-}$ mice administered $B 6$ or $F C \gamma R^{-/-}$mouse NKT cells 10 days after $\mathrm{K} / \mathrm{BxN}$ serum transfer. Results are representative of 3 independent experiments. ${ }^{*} P<0.05 ;{ }^{* *} P<0.01$. 
A
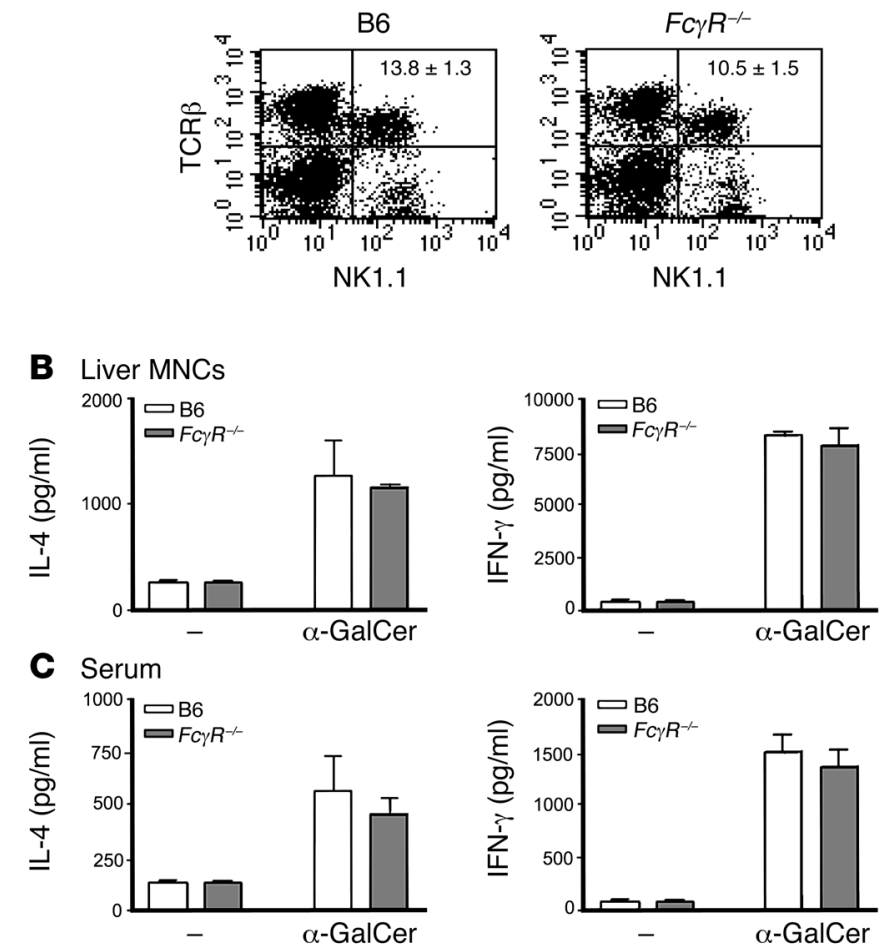
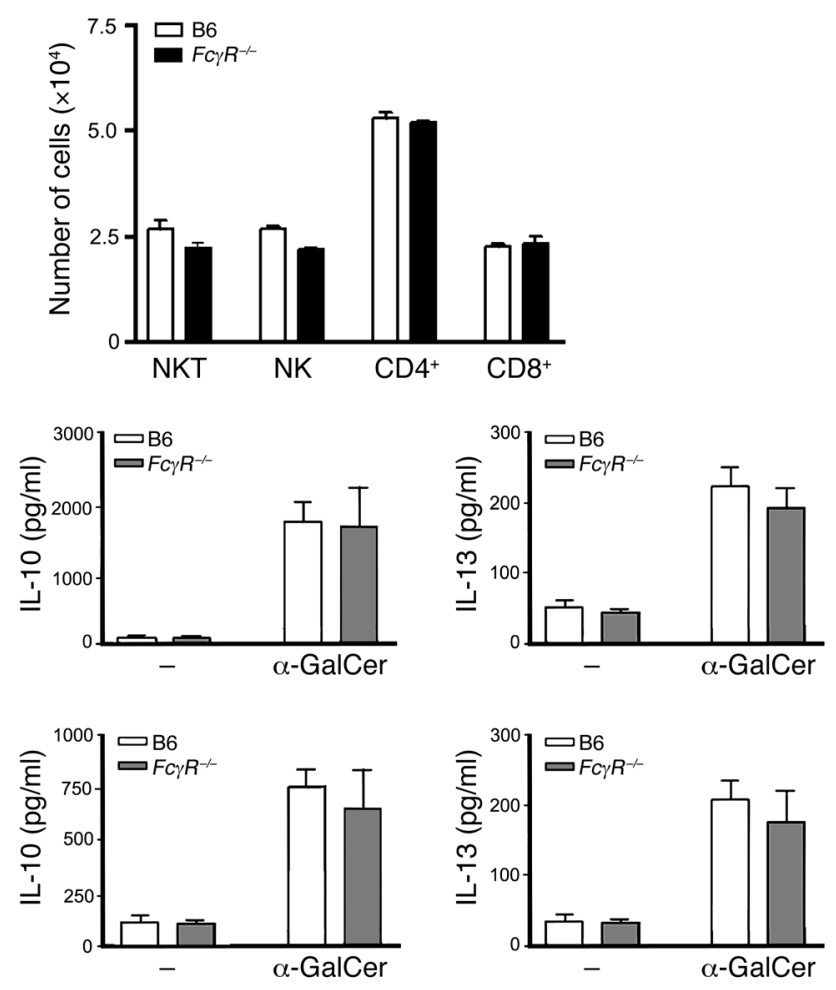

Figure 4

FC $\gamma R$-deficient NKT cells are activated by $\alpha$-GalCer. (A) Liver MNCs were freshly isolated from B6 or FC $R^{-1-}$ mice and analyzed for NKT cells by examining NK1.1 and TCR $\beta$ expression using flow cytometry. The numbers of NK, NKT, CD4+, and CD8 $8^{+}$cells were also counted. (B) Liver MNCs were freshly isolated from B6 or $F c \gamma R^{-1-}$ mice and cultured with $\alpha-G a l C e r(220 \mathrm{ng} / \mathrm{ml})$ for 48 hours. The amounts of IL-4, IFN- $\gamma$, IL-10, and IL-13 in the culture supernatants were measured using ELISA. (C) B6 and $F c \gamma R^{-/-}$mice were injected i.p. with $\alpha$-GalCer (1 $\mu$ in $300 \mu \mathrm{I}$ PBS). Serum IL-4, IFN- $\gamma$, IL-10, and IL-13 levels were monitored using ELISA 12 hours after $\alpha$-GalCer injection. Data are mean \pm SD for 3 mice per group. Similar results were obtained from 3 independent experiments.

Histological examination of the ankle joints of $C D 1 d^{-/-}$mice administered NKT cells from B6 mice at day 5 after serum transfer revealed marked neutrophil infiltration of the synovium. In contrast, $C D 1 d^{-/-}$mice administered NKT cells from $F c \gamma R^{-/-}$mice showed mild inflammatory cell infiltration in the ankle joints (Figure 3B). To confirm the infiltration of NKT cells in joint tissues, we measured the V $\alpha 14 J \alpha 218$ TCR mRNA level in the joint tissues of $\mathrm{CD} 1 d^{-/-}$mice administered NKT cells from B6 or $\mathrm{FC} \mathrm{R}^{-/-}$ mice after $\mathrm{K} / \mathrm{BxN}$ serum transfer. RT-PCR showed the presence of $V \alpha 14 J \alpha 218$ TCR mRNA in the joint tissues of CD1 $d^{-/-}$mice administered NKT cells from B6 and $F c \gamma R^{-/-}$mice at 10 days after serum injection. The presence of Va14J 218 TCR mRNA was not demonstrated in CD1 $d^{-/-}$mice (Figure 3C). Moreover, real-time PCR demonstrated that the concentration of Va14Ja218 TCR mRNA in the joint tissues of $C D 1 d^{-/-}$mice administered $\mathrm{B} 6$ mouse NKT cells was similar to that of the joint tissues of $C D 1 d^{-/-}$mice administered $F c \gamma R^{-/-}$mouse NKT cells (Figure 3C). Taken together, these results suggest that primarily Fc $\gamma$ RIII engagement, rather than TCR engagement, contributes to NKT cell activation in this $\mathrm{K} / \mathrm{BxN}$ serum transfer model.

To rule out the possibility that the failure in restoration of joint inflammation in $C D 1 d^{-/-}$mice administered $F C \gamma R^{-/-}$mouse NKT cells might be due to a functional defect of $F c \gamma R$-deficient NKT cells, we examined the functional activity of NKT cells from $F c \gamma R^{-/-}$ mice by measuring hepatic NKT cell numbers in $F c \gamma R^{-/-}$and WT mice and cytokine production by NKT cells stimulated with $\alpha$ GalCer in both animal types. The numbers of NKT, NK, CD4 ${ }^{+}$, and $\mathrm{CD}^{+}$cells in $\mathrm{Fc}_{\mathrm{C}} \mathrm{R}^{-/-}$mouse livers were similar to those in WT mouse livers (Figure 4A). Furthermore, when liver MNCs from $F c \gamma R^{-/-}$mice were stimulated with $\alpha$-GalCer, the production of IL-4, IL-10, IL-13, and IFN- $\gamma$ was enhanced, as in MNCs from B6 mice (Figure 4B). Consistent with our in vitro experiments, the production of IL-4, IL-10, IL-13, and IFN- $\gamma$ in sera from $F c \gamma R^{-/-}$ mice injected with $\alpha$-GalCer was also similar to that in sera from WT B6 mice (Figure 4C). These findings indicate that $F c \gamma R$-deficient NKT cells are functionally intact in terms of activation by $\alpha$-GalCer/CD1d complexes.

To explore the mechanism by which surface Fc $\gamma$ RIII on NKT cells contributes to the development of arthritis, we used real-time PCR to measure the levels of $I L-4, I F N-\gamma$, and TGF- $\beta$ in the synovia of $C D 1 d^{-/-}$mice administered NKT cells from B 6 or $F c \gamma R^{-/-}$mice. Upon $\mathrm{K} / \mathrm{BxN}$ serum transfer, $C D 1 d^{-/-}$mice administered NKT cells from $B 6$ mice showed a reduced level of TGF- $\beta 1$ on day 10 , as did B6 mice, whereas CD1 $d^{-/-}$mice administered NKT cells from $F c \gamma R^{-1-}$ mice showed an elevated level of TGF- $\beta 1$, as did $C D 1 d^{-/-}$ mice (Figure 3D). Conversely, IFN- $\gamma$ and $I L-4$ levels were lower in the joint tissues of $C D 1 d^{-/-}$mice administered NKT cells from $F c \gamma R^{-/-}$mice than in those administered NKT cells from B6 mice. In contrast to the levels in the joint tissues, the levels of TGF- $\beta 1$, $I L-4$, and $I F N-\gamma$ in the spleen were similar between $C D 1 d^{-/-}$mice 
administered NKT cells from $\mathrm{B} 6$ and $F c \gamma R^{-/-}$mice in the $\mathrm{K} / \mathrm{BxN}$ serum transfer model. These results indicate that Fc $\gamma$ RIII engagement on NKT cells by IgG deposited in joint tissues enhances the production of $I L-4$ and $I F N-\gamma$, thereby suppressing TGF- $\beta 1$ production, as previously reported (8).

\section{Discussion}

Our study demonstrates that $F c \gamma R$-deficient NKT cells induce less antibody-induced arthritis than do NKT cells of wild-type mice, although the expression level of Fc $\gamma$ RIII on NKT cells is relatively low. These findings suggest that primarily Fc $\gamma \mathrm{RIII}$ engagement, rather than TCR engagement, contribute to NKT cell activation in this $\mathrm{K} / \mathrm{BxN}$ serum transfer model. To address this suggestion, the possibility that $F c \gamma R$-deficient NKT cells may be functionally defective in activating processes, thereby contributing the failure to induce arthritis in $C D 1 d^{-/-}$mice, will need to be examined in future studies. The ability of $F c \gamma R$-deficient NKT cells stimulated with $\alpha$-GalCer to induce cytokine production in vitro and in vivo indicates that $F c \gamma R$-deficient NKT cells are functionally intact in terms of activation by $\alpha$-GalCer/CD1d complexes (Figure 4, B and C). Therefore, it is unlikely that the failure to induce arthritis in $C D 1 d^{-/-}$mice injected with $F c \gamma R$-deficient NKT cells was attributable to functional defects in NKT cells. Alternatively, it may have been the results of a failure of $F c \gamma R$-deficient NKT cells to

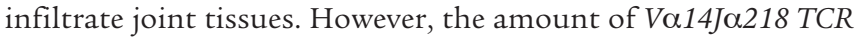
mRNA in joint tissues of $C D 1 d^{-/-}$mice administered B 6 mouse NKT cells appeared to be similar to that of CD1d $d^{-/-}$mice administered $F c \gamma R^{-/-}$mouse NKT cells in real-time PCR (Figure 3C). $\mathrm{Fc}_{\mathrm{RIII}}{ }^{+} \mathrm{NKT}$ cells in the joint tissues are a mixed population consisting of iNKT and non-iNKT cells. Moreover, the concentration of V $14 \mathrm{~J} \alpha 218$ TCR mRNA in the joint tissues reflects the number of iNKT cells but not non-iNKT cells. Therefore, these findings indicate that $F c \gamma R$-deficient iNKT cells infiltrate the joint tissues during joint inflammation, much as B6 iNKT cells do. However, during $\mathrm{K} / \mathrm{BxN}$ serum-transferred arthritis, both $C D 1 d^{-/-}$and $J \alpha 218^{-/-}$mice showed mild inflammatory cell infiltration in ankle joints and surrounding connective tissues compared with wild-type $\mathrm{B} 6$ mice, and the in vivo activation of NKT cells using $\alpha$-GalCer aggravated joint inflammation (8). These previous results suggest that iNKT cells contribute to the promotion of joint inflammation in the $\mathrm{K} / \mathrm{BxN}$ serum transfer model more than non-iNKT cells do. Therefore, the resistance to arthritis in the adoptive transfer experiments of $F c \gamma R$-deficient NKT cells into CD1 $1 d^{-/}$mice was probably caused by the failure of NKT cell activation through FcyRIII signals in the joint tissues.

Our present results revealed that Fc $\gamma$ RIII engagement by IgG in joint tissues provides activating signals to NKT cells in antibody-induced arthritis. It is generally believed that the engagement of TCR on NKT cells by $\alpha$-GalCer/CD1d provides primary activating signals for NKT cell activation in vitro and in vivo $(3,5)$. Molecules such as CD28, CD40, glucocorticoid-induced TNF receptor, and ICOS provide synergistic activating signals to NKT cells acting as costimulatory factors in the presence of simultaneous TCR engagement and thus modulate Th1/Th2 immune responses in vivo (23-25). Unlike these molecules, Fc $\gamma$ RIII induced NKT cell activation even in the absence of simultaneous TCR engagement in vitro, suggesting that Fc $\gamma$ RIII provides sufficient activating signals to NKT cells independently of TCR signals. The surface molecules expressed on T or NKT cells have not previously been reported to provide signals suffi- cient to activate these cells without simultaneous TCR engagement. Therefore our study elucidates, for the first time to our knowledge, the crucial role of FcyRIII in NKT cell activation in the absence of simultaneous TCR stimulation in vivo.

Several prior reports demonstrated that $F c \gamma R^{-/-}$mice are resistant to the induction or spontaneous onset of various autoimmune diseases $(13,26,27)$, and NKT cells are critically involved in the development of these diseases $(7,8,10)$. Those reports suggest that the activating function of FcrRIII on NKT cells might not be confined to antibody-induced joint inflammation, but play critical roles in the development of various immune complex-associated autoimmune diseases.

To our knowledge, the activating process of NKT cells by Fc $\gamma$ RIII engagement has never been considered during the development of therapeutic approaches to antibody-induced joint inflammation. In the $\mathrm{K} / \mathrm{BxN}$ serum transfer model, CSF-1dependent macrophages induced the expression of inhibitory Fc $\gamma$ RIIB on CSF-1-independent effector macrophages, and this resulted in protection from antibody-induced arthritis by intravenous immunoglobulin (IVIG) (28). These findings suggest that Fc $\gamma$ RIIb on immune cells may be responsible for mediating protection by IVIG and further suggest that NKT cells may not be strong candidates for therapeutic approaches using IVIG in a $\mathrm{K} / \mathrm{BxN}$ serum transfer model. Using combinatorial chemistry approaches, Marino et al. identified a peptide able to bind Ig and to interfere with $\mathrm{Fc} \gamma \mathrm{R}$ recognition (29). The administration of this peptide to $M R L / l p r$ mice, a lupus animal model, resulted in a remarkable enhancement of survival rate, which suggested that treatment based on the administration of molecules capable of interfering with $\mathrm{Ig} /$ receptor recognition could provide notable therapeutic benefit. However, as far as NKT cells are concerned, the role of FcyRIII on NKT cells has not previously been characterized to our knowledge in the development of lupus. Therefore, any potential therapeutic utility of targeting Fc $\gamma$ RIII on NKT cells in the treatment of lupus remains unknown and should be studied in the future. Unlike in lupus, a novel therapeutic approach targeted at specifically blocking FcrRIII on NKT cells may be useful for modulating joint inflammation induced by NKT cells in autoantibody-induced arthritis.

In conclusion, the current study reveals that FcrRIII engagement by IgG in joint tissues provides activating signals to NKT cells and thereby promotes antibody-induced joint inflammation.

\section{Methods}

Mice. The KRN TCR transgenic mice and NOD mice were gifts from D. Mathis and C. Benoist (Harvard Medical School, Boston, Massachusetts, USA) and from the Institut de Genetique et de Biologie Moleculaire et Cellulaire, and were maintained in a $\mathrm{B} 6$ background (K/B). Arthritic mice $(\mathrm{K} / \mathrm{BxN})$ were obtained by crossing $\mathrm{K} / \mathrm{B}$ with $\mathrm{NOD}(\mathrm{N})$ mice. The $\mathrm{CD} 1 \mathrm{~d}^{-/-}$ mice were a gift from $\mathrm{H}$. Gu (Columbia University, New York, New York, USA). The Fcerlg- $\mathrm{g}^{--}\left(\mathrm{FC \gamma R}^{--}\right)$mice of $\mathrm{B} 6$ background were purchased from Taconic. The B6 mice were purchased from Orient. These mice were bred and maintained under specific pathogen-free conditions at the Clinical Research Institute Seoul National University Hospital (CRISNUH), Seoul, Republic of Korea. All animal experiments were approved by the Institutional Animal Care and Use Committee at CRISNUH.

Cell line. DN32-D3 hybridoma (obtained from a V $\alpha 14^{+} T C R$ mouse with $C D 1 d$-specific NKT cells) were gifts from A. Bendelac (University of Chicago, Chicago, Illinois, USA) and were maintained in DMEM supplemented with $10 \%$ FBS and $5 \%$ of an antibiotic mix. 
Flow cytometry. The mAbs used were FITC-conjugated 2.4G2, PE-conjugated anti-mouse CD25, PE-conjugated anti-mouse CD69, FITC- or PE-conjugated anti-mouse NK1.1, CyChrome-conjugated anti-mouse TCR- $\beta$, FITC-conjugated anti-mouse CD4, and CyChrome-conjugated anti-mouse CD8 (BD Biosciences). The Fc $\gamma$ RII-specific mAb (Ly17.2) was a generous gift from U. Hammerling (Memorial Sloan-Kettering Cancer Center, New York, New York, USA). Cells $\left(1 \times 10^{6}\right)$ were stained with mAbs for 30 minutes at $4^{\circ} \mathrm{C}$.

Western blot. NKT cells sorted from B 6 mouse liver and DN32-D3 cells were stimulated with and without heat-aggregated IgG, which was prepared by heating purified IgG at $63^{\circ} \mathrm{C}$ for 20 minutes. Proteins were eluted using extraction reagent (NE-PER Nuclear and Cytoplasmic Extraction Reagents; Pierce Biotechnology). Proteins were separated on SDS-PAGE and transferred to Nitrocellulose Membranes (Protran; Schleicher \& Schuell Bioscience). Visualization was achieved using appropriate secondary Abs coupled to HRP, developed using the Abs indicated in Figure 2B and detected by ECL. Anti-GATA-3, anti-T-bet, anti-Syk, and anti-Lyn antibodies were purchased from Santa Cruz Biotechnology Inc. The antiphosphotyrosine antibody, 4G10, was purchased from Upstate USA Inc.

ELISA. Sorted NKT cells $\left(1 \times 10^{5}\right.$ cells/well $)$ were stimulated using the concentrations indicated in Figure 2, C-E, of anti-CD3 mAb and/or aggregated IgG or $\alpha$-GalCer for 48 hours. All cytokine ELISA kits were obtained from $\mathrm{BD}$ Biosciences, and assays were performed according to the manufacturer's instructions. Standard curves were generated using known amounts of purified murine recombinant IL-4 (rIL-4), rIL-10, rIL-13, or rIFN- $\gamma$ (BD Biosciences). The reaction was stopped with $3 \mathrm{~N}$ hydroxy acid, and absorbance was read at $450 \mathrm{~nm}$ and $570 \mathrm{~nm}$.

Real-time PCR and RT-PCR analysis. For quantitative real-time PCR, total RNA was isolated from joint tissue homogenates using an RNeasy kit (QIAGEN) according to the manufacturer's instructions. RNA was reverse transcribed with MMLV-RT Taq polymerase (Koschem) prior to PCR. cDNA $(1 \mu \mathrm{g})$ was amplified in the presence of a TaqMan universal master mix (PerkinElmer), gene-specific probes, the forward and reverse primers, and water. Gene-specific PCR products were measured using an Applied Biosystems 7500 Sequence Detection System (PerkinElmer, Applied Biosystems), and results for each cytokine were normalized to GAPDH expression. For real-time PCR, the following primers were synthesized by Applied Biosystems: GAPDH forward, TGCACCACCAACTGCTTA, reverse, GGATGCAGGGATGATGTT, and probe, CAGAAGACTGTGGATGGCCCCTC-VIC; IFN- $\gamma$ forward, AGCAACAGCAAGGCGAAAA, reverse, CTGGACCTGTGGGTTGTTGA, and probe, CTCAAACTTGGCAATACTCATGAATGCATC-TAMRA; IL-4 primers used were PrimeScreen Mouse IL-4 Primer Pair and probe, FAMCTCCGTGCATGGGGTCCCTTC-Black Hole Quencher (BioSource International); TGF- $\beta 1$ forward, GCAACATGTGGAACTCTACCAGAA, reverse, GACGTCAAAAGACAGCCACTCA, and probe, ACCTTGGTAACCGGCTGCTGACCC-TAMRA; V $\alpha 14 \mathrm{~J} \alpha 218$ TCR forward, GTGTGGTGGGCGATAGAGGT, reverse, ACAACCAGCTGAGTCCCAGC, and probe, FAM-CAGCCTTAGGGAGGCTGCATTTTGG-TAMRA.
For RT-PCR, the following primers were synthesized by Genotech Corp: Fc $\gamma$ RI forward, GTTAATTGCCACCAAGGCTGT, reverse, ACCTGTATTCGCCACTGTCC; Fc $\gamma$ RII forward, AGTCCAAGCCTGTCACCATC, reverse, CAGTTTTGGCAGCTTCTTCC; Fc $\gamma$ RIII forward, TGACACCCCATCCATCCTAT, reverse, CCCAGGATCTCACTGGGTTA; FcyRIV forward, ATCTGCTCTAGAAGCATGTGGCAGCTACTA, reverse, CATGCGATAAGAGCTCACTTGTCCTGAGGT; Va14Ja18 TCR forward, CTAAGCACAGCACGCTGCACA, reverse, AGGTATGACAATCAGCTGAGTCCC.

Serum transfer and arthritis scoring. Arthritic adult $\mathrm{K} / \mathrm{BxN}$ mice were bled, and sera were pooled. Recipient mice were injected i.p. with $150 \mu$ l of pooled $\mathrm{K} / \mathrm{BxN}$ sera on days 0 and 2 relative to the first injection. Ankle thickness was measured with a caliper (Manostat). Joint swelling was monitored and scored as follows: 0 , no joint swelling, 1 , swelling of a single finger joint, 2 , mild swelling of a wrist or ankle, and 3 , severe swelling of a wrist or ankle.

Adoptive transfer. Liver NKT cells were stained using PE-conjugated anti-NK1.1 and CyChrome-conjugated anti-TCR- $\beta$ mAbs, and NK1.1 $1^{+}$TCR $-\beta^{+}$NKT cells were sorted using FACStar PLUS and CellQuest software (version 3.3; BD) to a purity of $>98 \%$. Sorted cells were adoptively transferred into $C D 1 d^{-/-}$mice via intravenous injection 1 day before the first injection of $\mathrm{K} / \mathrm{BxN}$ serum.

Histology. Joints were fixed in $10 \%$ formalin, decalcified by $10 \%$ EDTA in PBS for 3 days, embedded in paraffin, and sectioned, and tissue sections from knee joints were stained with hematoxylin and eosin.

Synthesis of $\alpha$-GalCer. $\alpha$-GalCer was synthesized using the method developed by Kim et al. (30).

Statistics. Statistical significance was analyzed using the Prism 3.0 program (GraphPad Software). To compare more than 2 groups, the 1-way ANOVA statistical analysis using Tukey test was performed. $P$ values less than 0.05 were considered significant.

\section{Acknowledgments}

The authors thank Seong Hoe Park for his support of this project, Kyeong Cheon Jung and Eun Young Choi for helpful comments on the manuscript, and all members of the Department of Experimental Animals at CRISNUH for animal management. We are also grateful to Uli Hammerling for providing Fc $\gamma$ RII-specific $\mathrm{mAb}$ (Ly17.2). This work was supported by a grant (R11-2002-09805002-0) from the Korean Science and Engineering Foundation through the Rheumatism Research Center.

Received for publication October 25, 2005, and accepted in revised form June 20, 2006.

Address correspondence to: Doo Hyun Chung, Department of Pathology and Graduate Program of Immunology, Seoul National University College of Medicine, 28 Yongon-dong, Chongno-gu, Seoul 110-799, Republic of Korea. Phone: 82-2-2072-2552; Fax: 822-743-5530; E-mail: doohyun@plaza.snu.ac.kr.
1. Lantz, O., and Bendelac, A. 1994. An invariant T cell receptor alpha chain is used by a unique subset of major histocompatibility complex class I-specific $\mathrm{CD}^{+}$and $\mathrm{CD} 4^{-} 8^{-} \mathrm{T}$ cells in mice and humans. J. Exp. Med. 180:1097-1106.

2. Bendelac, A. 1995. CD1: presenting unusual antigens to unusual T lymphocytes. Science. 269:185-186.

3. Kawano, T., et al. 1997. CD1d-restricted and TCRmediated activation of valpha14 NKT cells by glycosylceramides. Science. 278:1626-1629.

4. Chen, H., and Paul, W.E. 1997. Cultured NK1.1 ${ }^{+}$ $\mathrm{CD}^{+} \mathrm{T}$ cells produce large amounts of IL-4 and IFN-gamma upon activation by anti-CD3 or CD1.
J. Immunol. 159:2240-2249.

5. Taniguchi, M., Harada, M., Kojo, S., Nakayama, T., and Wakao, H. 2003. The regulatory role of Valpha14 NKT cells in innate and acquired immune response. Annu. Rev. Immunol. 21:483-513.

6. Beaudoin, L., Laloux, V., Novak, J., Lucas, B., and Lehuen, A. 2002. NKT cells inhibit the onset of diabetes by impairing the development of pathogenic $\mathrm{T}$ cells specific for pancreatic beta cells. Immunity. 17:725-736

7. Singh, A.K., et al. 2001. Natural killer T cell activation protects mice against experimental autoimmune encephalomyelitis. J. Exp. Med. 194:1801-1811.
8. Kim, H.Y., et al. 2005. NKT cells promote antibodyinduced joint inflammation by suppressing transforming growth factor $\beta 1$ production. J. Exp. Med. 201:41-47.

9. Kim, J.H., et al. 2005. Natural killer T (NKT) cells attenuate bleomycin-induced pulmonary fibrosis by producing interferon- $\gamma$. Am. J. Pathol. 167:1231-1241.

10. Zeng, D., Liu, Y., Sidobre, S., Kronenberg, M., and Strober, S. 2003. Activation of natural killer T cells in NZB/W mice induces Th1-type immune responses exacerbating lupus. J. Clin. Invest. 112:1211-1222. doi:10.1172/JCI200317165. 
11. Gumperz, J.E., et al. 2000. Murine CD1d-restricted $\mathrm{T}$ cell recognition of cellular lipids. Immunity. 12:211-221.

12. Ji, H., et al. 2002. Arthritis critically dependent on innate immune system players. Immunity. 16:157-168.

13. Corr, M., and Crain, B. 2002. The role of FcgammaR signaling in the $\mathrm{K} / \mathrm{B} \times \mathrm{N}$ serum transfer model of arthritis. J. Immunol. 169:6604-6609.

14. Takai, T. 2002. Roles of Fcreceptors in autoimmunity. Nat. Rev. Immunol. 2:580-592.

15. Koyasu, S. 1994. CD ${ }^{+}$CD $16^{+}$NK1.1 ${ }^{+}$B $220^{+}$large granular lymphocytes arise from both alpha-beta $\mathrm{TCR}^{+} \mathrm{CD}^{-} \mathrm{CD}^{-}$and gamma-delta $\mathrm{TCR}^{+} \mathrm{CD} 4$ CD8- cells. J. Exp. Med. 179:1957-1972.

16. Unkeless, J.C. 1979. Characterization of a monoclonal antibody directed against mouse macrophage and lymphocyte Fc receptors. J. Exp. Med. 150:580-596.

17. Takai, T., Li, M., Sylvestre, D., Clynes, R., and Ravetch, J.V. 1994. FcR gamma chain deletion results in pleiotrophic effector cell defects. Cell. 76:519-529.

18. Nimmerjahn, F., Bruhns, P., Horiuchi, K., and Ravetch, J.V. 2005. FcgammaRIV: a novel FcR with distinct $\operatorname{IgG}$ subclass specificity. Immunity. 23:41-51.

19. Marcilla, A., Rivero-Lezcano, O.M., Agarwal, A., and Robbins, K.C. 1995. Identification of the major tyrosine kinase substrate in signaling complexes formed after engagement of Fc gamma receptors. J. Biol. Chem. 270:9115-9120.

20. Crowley, M.T., et al. 1997. A critical role for Syk in signal transduction and phagocytosis mediated by Fcgamma receptors on macrophages. J. Exp. Med. 186:1027-1039.

21. Szabo, S.J., et al. 2000. A novel transcription factor, T-bet, directs Th1 lineage commitment. Cell. 100:655-669.

22. Ouyang, W., et al. 1998. Inhibition of Th1 development mediated by GATA- 3 through an IL-4-independent mechanism. Immunity. 9:745-755.

23. Hayakawa, Y., et al. 2001. Differential regulation of Th1 and Th2 functions of NKT cells by CD28 and CD40 costimulatory pathways. J. Immunol. 166:6012-6018.

24. Kaneda, H., et al. 2005. ICOS costimulates invariant NKT cell activation. Biochem. Biophys. Res. Commun. 327:201-207.

25. Kim, H.J., Kim, H.Y., Kim, B.K., Kim, S., and Chung,
D.H. 2006. Engagement of glucocorticoid-induced TNF receptor costimulates NKT cell activation in vitro and in vivo. J. Immunol. 176:3507-3515.

26. Butkiewicz, L., Duriagin, S., Laddach, R., Chwalinska-Sadowska, H., and Jagodzinski, P.P. 2005. Prevalence of $\mathrm{Fc}$-gammaR chain expression in CD4+ T cells of patients with systemic lupus erythematosus. Scand. J. Rheumatol. 34:216-219.

27. Abdul-Majid, K.B., et al. 2002. Fc receptors are critical for autoimmune inflammatory damage to the central nervous system in experimental autoimmune encephalomyelitis. Scand. J. Immunol. 55:70-81.

28. Bruhns, P., Samuelsson, A., Pollard,J.W., and Ravetch, J.V. 2003. Colony-stimulating factor-1-dependent macrophages are responsible for IVIG protection in antibody-induced autoimmune disease. Immunity. 18:573-581.

29. Marino, M., Ruvo, M., De Falco, S., and Fassina, G. 2000. Prevention of systemic lupus erythematosus in MRL/lpr mice by administration of an immunoglobulin-binding peptide. Nat. Biotechnol. 18:735-739.

30. Kim, S.L.S., Lee, T., Jung, S., and Kim, D. 2004. Practical synthesis of KRN7000 form phytosphingosine. Synthesis. 22:847-850. 